\title{
Características agroindustriais da cana-de-açúcar em função da adubação fosfatada, em solos de Pernambuco
}

\author{
Djalma E. Simões $\mathrm{N}$ eto $^{1}$, Alexandre $\mathrm{C}$. de 0 liveira $^{1}$ Alexandre $\mathrm{T}$. da Rocha ${ }^{2}$, \\ Fernando J. Freire ${ }^{3}$, Maria B. G. dos S. Freire ${ }^{3} \&$ Clístenes W. A. do Nascimento $^{3}$
}

\section{RESU M O}

As recomendações para adubação fosfatada no $\mathrm{N}$ ordeste do Brasil não só estão baseadas em trabalhos conduzidos nas décadas de 70 e 80, mas requerem sua comendação que, especificamente no caso do fósforo, leve em consideração a capacidade máxima de adsorção de fosfato (CM AP); objetivou-se, então, avaliar as características agroindustriais da cana-de-açúcar em solos de Pernambuco em função da adubação fosfatada. Cinco experimentos foram conduzidos na Zona da M ata do Estado. O s solos foram classificados como: Argissolo Amarelo distrocoeso (PAdx); Latossolo Amarelo distrófico (LAd); Argissolo Amarelo distrófico (PAd); G leissolo háplico eutrófico (GXve) e Espodossolo cárbico duripânico (EKo). Os tratamentos consistiram de sete doses de fósforo, determinadas em função da CMAP. O delineamento experimental foi em blocos ao acaso, com quatro repetições. As variedades utilizadas foram a RB863129, nos solos PAd, LAd, GXve e EKo e a RB855536, no PAD. A adubação fosfatada em cana planta influenciou positivamente as produtividades agrícola e industrial. Os valores de açúcares totais recuperáveis (ATR) não foram influenciados pela adubação fosfatada mas foram mais elevados nos solos com maior CMAP.

Palavras-chave: Sacharum SPP, produtividade, qualidade tecnológica

\section{Industrial characteristics of sugarcane under phosphate fertilization in soils of Pernambuco Brazil}

\begin{abstract}
The $P$ recommendations in N ortheastern Brazil are based on research carried out in the decades of 70 and 80 , being necessary a modernization in this recommendation, to focus the maximum capacity of $P$ adsorption. Therefore, this work aimed to evaluate agroindustrial sugarcane characteristics in soils in function of phosphate fertilization. Five experiments were carried out at Pernambuco State Forest Zone Region. The soils were: Argisoil Yellow distrocoeso (PAdx); Latosoil Yellow distrofic (LAd); Argisoil Yellow distrofic (PAd); Gleisoil haplic eutrofic (GXve); and Espodosoil carbic duripanic (ESKo). The treatments consisted of seven $P$ doses, determined in function of the maximum adsorption capacity of $P$. The experimental design was a completely randomized block, with four replications. The sugarcane variety RB863129 was used in PAd, LAd, GXve and EKo soils and RB855536 on PAd soil. The P fertilization increased agricultural and industrial productivities. Total recoverable sugar (ATR) values were not affected by phosphate fertilizer, being more elevated in soils with higher maximum adsorption capacity of $P$.
\end{abstract}

Key words: Sacharum SPP, productivity, technological quality

\footnotetext{
Estação Experimental de Cana-de-açúcar do Carpina/U FRPE. Rua Ângela Cristina de Luna, Bairro Novo, CP 40, CEP 55819-225, Carpina, PE. Fone: (81) 3622-0444, Fax: (81) 3622-0244. E-mail: desn@oi.com.br

2 U nidade Acadêmica de Serra Talhada/U FRPE. Fazenda Saco, s/n, CP 63, CEP 56900-000, Serra Talhada, PE. Fone: (87) 3831-1927. E-mail: alexandre@uast.ufrpe.br

3 Departamento de Agronomia/UFRPE. Rua Dom Manoel de Medeiros, Campus Universitário de Dois Irmãos, CEP 52171-900, Recife, PE. Fone: (81) 3320-6223, Fax: (81) 3320-6220. E-mail: f.freire@depa.ufrpe.br; betania@depa.ufrpe.br; clistenes@depa.ufrpe.br
} 


\section{INTRODUÇÃO}

No Estado de Pernambuco a agroindústria da cana-deaçúcar ocupa uma elevada área agrícola e uma relevante produção de açúcar e álcool, gerando muitos empregos diretos nas áreas rural e industrial proporcionando, desta forma, grande contribuição social.

Embora o fósforo seja exigido em pequenas quantidades pela cana-de-açúcar, comparado com o nitrogênio e potássio, ele exerce funções primordiais no metabolismo da planta, particularmente na formação de proteínas, na divisão celular, na fotossíntese, no armazenamento de energia, no desdobramento do açúcar, na respiração, no fornecimento de energia e na produção de sacarose (Oliveira et al., 2005).

A presença de fósforo no caldo da cana-de-açúcar exerce papel fundamental no processo de clarificação. Caldos contendo baixos teores deste elemento são de difícil floculação e, neste caso a decantação das impurezas (bagacilho, argila, clorofila, entre outros) é reduzida. Caldo turvo e de coloração intensa implica na produção de açúcar de pior qualidade e, portanto, de menor valor comercial, chegando a inviabilizar o produto para exportação, devido às exigências de cor (Bovi \& Serra, 2001). Desta forma, a qualidade dos produtos da canade-açúcar pode ser, dentre outros fatores, dependente do manejo da adubação (Dantas Neto et al., 2006)

Nos solos cultivados com cana-de-açúcar em Pernambuco, a assimilação do fósforo pela planta é dificultada visto que a cultura está instalada em solos altamente intemperizados com condições propícias para elevada fixação do elemento. Assim, os solos são muito mais dreno do que fonte de fósforo, competindo com a planta pelo fosfato adicionado via fertilizante. São solos que possuem elevada capacidade máxima de adsorção de P (CMAP), fazendo com que o fósforo da fonte fosfatada, adicionada ao solo, passe gradativamente da forma lábil para a não lábil (Broggi et al., 2010), limitando a produtividade da cultura e exigindo mais o uso do nutriente na adubação. $\mathrm{O}$ aumento da disponibilidade de fósforo pode ser obtido pelo manejo da adubação fosfatada e pela escolha do fertilizante adequado para cada tipo de solo (Simões Neto et al. 2009).

Resultados experimentais de Morelli et al. (1991), mostraram uma resposta maior da cana-de-açúcar ao fósforo, quando o nutriente foi aplicado todo no fundo do sulco, não havendo necessidade de adubação em soqueiras. Santos et al. (2009), não observaram efeito da aplicação de fósforo nas variáveis de crescimento em cana planta e atribuíram tal comportamento ao efeito residual do fósforo aplicado em cultivos anteriores. No entanto, Demattê (2005), considerando uma produção ao longo de cinco colheitas, de 400 toneladas de colmos de canade-açúcar, fez um cálculo sobre o balanço de fósforo no solo utilizando uma dose de $150 \mathrm{~kg} \mathrm{ha}^{-1}$ de $_{2} \mathrm{O}_{5}$ no plantio, extração de $0,43 \mathrm{~kg}$ de fósforo por tonelada de massa verde e fixação de fósforo de $30 \%$ e neste balanço o autor constatou déficit de fósforo,que deve ser reposto nas soqueiras, desde que associado à aplicação de calcário.

Em Pernambuco e conforme indicado nas Recomendações de Adubação para o Estado de Pernambuco (IPA, 2008), tanto os solos arenosos como os argilosos têm a mesma recomendação de fósforo, quando pesquisas mais recentes (Silva et al., 2003; Silva et al., 2004; Corrêa et al., 2008; Simões Neto et al., 2009) indicam que a capacidade tampão dos solos é de fundamental importância na dinâmica deste elemento no sistema solo-planta.

Objetivou-se então, com este trabalho, avaliar as características agroindustriais da cana-de-açúcar cultivada em diferentes solos de Pernambuco, em função da adubação fosfatada, evitando desperdícios e atendendo adequadamente às exigências nutricionais da planta, que possam promover incrementos nos teores de açúcar, em diferentes solos.

\section{Material e mÉtodos}

Os experimentos foram conduzidos em condições de campo na Zona da Mata do Estado de Pernambuco, em solos intemperizados de diferentes composições físicas, químicas e mineralógicas (Tabela 1). Nessas áreas as características edafoclimáticas são distintas, caracterizando a Zona da Mata em cinco regiões: Norte, Litoral Norte, Centro, Sul e Litoral Sul.

Tabela 1. Identificação dos solos e localização dos experimentos de campo

\begin{tabular}{|c|c|c|}
\hline Identificação/classe & Localização & Municípios \\
\hline $\begin{array}{l}\text { PAdx - Argissolo Amarelo } \\
\text { Distrocoeso }\end{array}$ & EECAC/UFRPE & Carpina/PE \\
\hline $\begin{array}{l}\text { LAd - Latossolo Amarelo } \\
\text { Distrófico }\end{array}$ & Usina Cucaú & Rio Formoso/PE \\
\hline $\begin{array}{l}\text { PAd - Argissolo Amarelo } \\
\text { Distrófico }\end{array}$ & Usina Pumaty & $\begin{array}{l}\text { Joaquim } \\
\text { Nabuco/PE }\end{array}$ \\
\hline $\begin{array}{l}\text { GXve - Gleissolo Háplico } \\
\text { Eutrófico }\end{array}$ & Usina Salgado & Ipojuca/PE \\
\hline $\begin{array}{l}\text { EKo - Espodossolo Humilúvico } \\
\text { Órtico }\end{array}$ & $\begin{array}{l}\text { Usina Santa } \\
\text { Tereza }\end{array}$ & Goiana/PE \\
\hline
\end{tabular}

Selecionadas as cinco áreas para instalação dos experimentos de campo, amostras dos solos foram retiradas na profundidade de 0,0-0,2 m; em seguida, foram secadas ao ar e passadas em peneira de $2 \mathrm{~mm}$ de abertura de malha, procedendose à sua caracterização física e química (Tabela 2).

Os solos foram caracterizados fisicamente pela composição granulométrica, utilizando-se o método do densímetro, densidade do solo pelo método do anel volumétrico, densidade das partículas pelo método do balão volumétrico, umidade na capacidade de campo e no ponto de murcha permanente, pela câmara de pressão e condutividade hidráulica em meio saturado com o permeâmetro de coluna vertical e carga constante, conforme indicado pela EMBRAPA (1997).

Quimicamente, os solos foram caracterizados pelos $\mathrm{pH}\left(\mathrm{H}_{2} \mathrm{O}\right) ; \mathrm{pH}(\mathrm{KCl}) ; \mathrm{Ca}^{2+} ; \mathrm{Mg}^{2+} ; \mathrm{Na}^{+} ; \mathrm{K}^{+} ; \mathrm{Al}^{3+} ;(\mathrm{H}+\mathrm{Al}) ; \mathrm{P} ; \mathrm{C} . ; \mathrm{P}-$

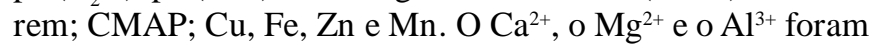
extraídos por $\mathrm{KCl}$ 1,0 mol L-1, o P, o K e os micronutrientes por Mehlich-1 e o $(\mathrm{H}+\mathrm{Al})$ por acetato de cálcio $0,5 \mathrm{~mol} \mathrm{~L}^{-1}$, conforme EMBRAPA (1997). O Ca ${ }^{2+}$ e o $\mathrm{Mg}^{2+}$ foram determinados por espectrofotometria de absorção atômica; o $\mathrm{K}^{+}$, por fotometria de chama e o P por colorimetria, conforme Braga \& Defelipo (1974; o $\mathrm{Al}^{3+}$ e o $(\mathrm{H}+\mathrm{Al})$ por titulometria e o $\mathrm{C}$ por combustão úmida com dicromato de potássio. 
Tabela 2. Características químicas e físicas dos solos das áreas experimentais

\begin{tabular}{|c|c|c|c|c|c|}
\hline Características & PAdx & LAd & PAd & GXve & EKo \\
\hline $\mathrm{pH}\left(\mathrm{H}_{2} \mathrm{O} \quad 1: 2,5\right)$ & 5,20 & 4,10 & 4,80 & 4,90 & 5,55 \\
\hline pH (KCl 1:2,5) & 4,00 & 3,60 & 3,80 & 3,60 & 4,40 \\
\hline $\mathrm{H}+\mathrm{Al}\left(\mathrm{cmol}_{\mathrm{c}} \mathrm{dm}^{-3}\right)$ & 5,20 & 9,24 & 7,00 & 6,77 & 3,22 \\
\hline $\mathrm{Al}^{3+}\left(\mathrm{cmol}_{\mathrm{c}} \mathrm{dm}^{-3}\right)$ & 0,35 & 2,00 & 1,00 & 1,20 & 0,00 \\
\hline $\mathrm{Ca}^{2+}\left(\mathrm{cmol}_{\mathrm{c}} \mathrm{dm}^{-3}\right)$ & 1,90 & 0,20 & 0,90 & 5,80 & 2,20 \\
\hline $\mathrm{Mg}^{2+}\left(\mathrm{cmol}_{\mathrm{c}} \mathrm{dm}^{-3}\right)$ & 0,50 & 0,20 & 0,50 & 2,20 & 0,50 \\
\hline $\mathrm{Na}^{+}\left(\mathrm{cmol}_{\mathrm{c}} \mathrm{dm}^{-3}\right)$ & 0,01 & 0,02 & 0,03 & 0,19 & 0,04 \\
\hline $\mathrm{K}^{+}\left(\mathrm{cmol}_{\mathrm{c}} \mathrm{dm}^{-3}\right)$ & 0,07 & 0,11 & 0,10 & 0,21 & 0,07 \\
\hline P-Melhich ( $\mathrm{mg} \mathrm{dm}^{-3}$ ) & 2,83 & 0,02 & 0,70 & 4,18 & 2,17 \\
\hline $\operatorname{CMAP}\left(\mathrm{mg} \mathrm{cm}^{-3}\right)^{1}$ & 0,33 & 0,67 & 0,78 & 0,82 & 0,10 \\
\hline P-rem $\left(\mathrm{mg} \mathrm{L}^{-1}\right)^{2}$ & 41,00 & 12,00 & 17,00 & 17,00 & 46,00 \\
\hline m (\%) & 12,36 & 79,03 & 39,46 & 12,50 & 0,00 \\
\hline V (\%) & 32,29 & 5,43 & 17,98 & 55,40 & 46,69 \\
\hline PST (\%) & 0,45 & 0,94 & 1,29 & 1,95 & 1,55 \\
\hline $\mathrm{CTC}_{\text {efetiva }}\left(\mathrm{cmol}_{\mathrm{C}} \mathrm{dm}^{-3}\right)$ & 2,83 & 2,52 & 2,53 & 9,60 & 2,81 \\
\hline $\mathrm{CTC}\left(\mathrm{cmol}_{\mathrm{c}} \mathrm{dm}^{-3}\right)$ & 7,68 & 9,76 & 8,53 & 15,17 & 6,03 \\
\hline $\mathrm{Cu}\left(\mathrm{mg} \mathrm{dm}^{-3}\right)^{3}$ & 1,05 & 0,85 & 0,35 & 2,40 & 0,60 \\
\hline $\mathrm{Fe}\left(\mathrm{mg} \mathrm{dm}^{-3}\right)^{3}$ & 76,40 & 140,30 & 190,15 & 215,00 & 52,40 \\
\hline $\mathrm{Zn}\left(\mathrm{mg} \mathrm{dm}^{-3}\right)^{3}$ & 1,50 & 1,30 & 0,85 & 3,85 & 1,35 \\
\hline$M n\left(m g d m^{-3}\right)^{3}$ & 6,20 & 1,12 & 1,15 & 52,00 & 5,60 \\
\hline$C\left(g_{k g}^{-1}\right)$ & 8,90 & 9,60 & 17,90 & 13,80 & 10,70 \\
\hline Areia $\left(\mathrm{g} \mathrm{kg}^{-1}\right)$ & 785,8 & 311,6 & 539,20 & 51,60 & 855,80 \\
\hline Silte $\left(\mathrm{g} \mathrm{kg}^{-1}\right)$ & 54,6 & 9,2 & 9,20 & 209,20 & 64,60 \\
\hline Argila $\left(\mathrm{g} \mathrm{kg}^{-1}\right)$ & 159,6 & 679,2 & 451,60 & 739,20 & 79,60 \\
\hline $\mathrm{Ds}\left(\mathrm{Mg} \mathrm{m}^{-3}\right)$ & 1,41 & 1,13 & 1,05 & 1,02 & 1,50 \\
\hline $\mathrm{Dp}\left(\mathrm{Mg} \mathrm{m}^{-3}\right)$ & 2,67 & 2,63 & 2,67 & 2,56 & 2,63 \\
\hline$\alpha\left(\mathrm{Mg} \mathrm{m}^{-3}\right)$ & 0,47 & 0,57 & 0,60 & 0,60 & 0,43 \\
\hline$C C\left(g^{-1}\right)$ & 0,09 & 0,35 & 0,25 & 0,66 & 0,06 \\
\hline $\operatorname{PMP}\left(\mathrm{g} \mathrm{g}^{-1}\right)$ & 0,05 & 0,19 & 0,17 & 0,21 & 0,02 \\
\hline $\mathrm{Ko}\left(\mathrm{cm} \mathrm{h}^{-1}\right)$ & 11,60 & 6,32 & 20,92 & 1,12 & 23,05 \\
\hline
\end{tabular}

${ }^{1}$ Capacidade máxima de adsorção de $\mathrm{P} ;{ }^{2} \mathrm{P}$ remanescente; ${ }^{3}$ Extrator Melhich-1

PAdx - Argissolo Amarelo Distrocoeso; LAd - Latossolo Amarelo Distrófico; PAd - Argissolo Amarelo Distrófico; GXve - Gleissolo Háplico Eutrófico; EKo - Espodossolo Humilúvico Órtico

O P-rem, que é a concentração de P na solução de equilíbrio após agitação durante $1 \mathrm{~h}$ da TFSA (terra fina secada ao ar) com solução de $\mathrm{CaCl}_{2} 10 \mathrm{mmol} \mathrm{L}^{-1}$ contendo $60 \mathrm{mg} \mathrm{L}^{-1} \mathrm{de} \mathrm{P}$, na relação de 1:10 (solo:solução), foi determinado de acordo com Alvarez V. et al. (2000).

Para avaliação da capacidade máxima de adsorção de fosfato (CMAP), as amostras de cada solo receberam doses de $\mathrm{P}$ baseadas no valor de P-rem (Alvarez V. \& Fonseca, 1990). Amostras de TFSA de cada solo foram saturadas com soluções de concentrações crescentes de $\mathrm{P}$ em $\mathrm{CaCl}_{2} 10 \mathrm{mmol} \mathrm{L}^{-1}$, adotando-se a isoterma de Langmuir para estimar a CMAP.

A análise mineralógica da fração argila dos solos foi realizada por difratometria de raios-X (Coffin, 1963), possibilitando a identificação dos minerais predominantes na fração argila dos solos (Tabela 3). Foram determinados, também, $\mathrm{Fe}$ amorfo, extraído por oxalato ácido de amônio $\left(\mathrm{FE}_{\mathrm{o}}\right)$ e $\mathrm{Fe}$ cristalino, extraído por ditionito - citrato - bicarbonato de sódio $\left(\mathrm{Fe}_{\mathrm{d}}\right)$, (Mehra \& Jackson, 1960), ambos determinados por espectrofotometria de absorção atômica (Tabela 3).

Os tratamentos consistiram em sete níveis de $\mathrm{P}$, determinados em função da CMAP (Tabela 4). As doses de P foram aplicadas no sulco de plantio e tiveram, como fonte, $\mathrm{O}$ superfosfato triplo. O delineamento experimental foi em blocos ao acaso, com quatro repetições, totalizando vinte e oito parcelas experimentais. Cada parcela foi constituída por sete linhas com dez metros de comprimento, utilizando-se como espaçamento $1 \mathrm{~m}$ entrelinhas, totalizando $70 \mathrm{~m}^{2}$ para área total
Tabela 3. Identificação dos minerais predominantes na fração argila dos solos, ferro amorfo $\left(\mathrm{Fe}_{0}\right)$ e cristalino $\left(\mathrm{Fe}_{\mathrm{d}}\right)$ e suas relações

\begin{tabular}{|c|c|c|c|c|}
\hline \multirow{2}{*}{ Solo* } & \multirow{2}{*}{ Minerais } & $\mathrm{Fe}_{0}$ & $\mathrm{Fe}_{\mathrm{d}}$ & \multirow{2}{*}{ Feo/Fed } \\
\hline & & \multicolumn{2}{|c|}{$\mathrm{g} \mathrm{kg}^{-1}$} & \\
\hline EKo & $\mathrm{Ct}, \mathrm{Qz}, \mathrm{Gt}$ & 0,38 & 1,14 & 0,33 \\
\hline GXve & $\mathrm{Mi}, \mathrm{Ct}, \mathrm{Qz}, \mathrm{Gb}$ & 1,47 & 2,27 & 0,65 \\
\hline PAd & $\mathrm{Ct}, \mathrm{Qz}, \mathrm{Gt}, \mathrm{Gb}$ & 2,03 & 15,51 & 0,13 \\
\hline LAd & $\mathrm{Ct}, \mathrm{Qz}, \mathrm{Gt}, \mathrm{Gb}$ & 1,63 & 15,04 & 0,11 \\
\hline PAdx & $\mathrm{Ct}, \mathrm{Qz}, \mathrm{Gt}$ & 0,54 & 1,39 & 0,39 \\
\hline
\end{tabular}

Ct - caulinita; Gb - gibsita; Gt - goethita; Qz - quartzo; Mi - mica

EKo - Espodossolo Humilúvico Órtico; GXve - Gleissolo Háplico Eutrófico; PAd - Argissolo Amarelo Distrófico; LAd - Latossolo Amarelo Distrófico; PAdx - Argissolo Amarelo Distrocoeso

Tabela 4. Níveis de fósforo em função da capacidade máxima de adsorção de fósforo e doses de fósforo aplicadas nos solos

\begin{tabular}{crrrrr}
\hline $\begin{array}{c}\text { Níveis de } \mathbf{P} \\
\text { (\% da CMAP) }\end{array}$ & PAdx & \multicolumn{5}{c}{ LAd } & PAd & GXve & EKo \\
\cline { 2 - 6 } da & \multicolumn{5}{c}{ Dose de $\mathbf{P}\left(\mathbf{k g ~ h a}^{-1}\right)$} \\
2 & 0,0 & 0,0 & 0,0 & 0,0 & 0,0 \\
4 & 13,2 & 25,4 & 30,0 & 32,8 & 4,0 \\
8 & 26,4 & 51,1 & 60,2 & 65,6 & 8,0 \\
12 & 52,8 & 102,2 & 126,4 & 131,2 & 16,0 \\
16 & 79,2 & 153,3 & 189,6 & 196,8 & 24,0 \\
20 & 105,6 & 204,4 & 252,8 & 262,4 & 32,0 \\
\hline
\end{tabular}

PAdx - Argissolo Amarelo Distrocoeso; LAd - Latossolo Amarelo Distrófico; PAd - Argissolo Amarelo Distrófico; GXve - Gleissolo Háplico Eutrófico; EKo - Espodossolo Humilúvico Órtico

e $30 \mathrm{~m}^{2}$ de área útil, após se desprezarem quatro linhas laterais, duas em cada lado da parcela.

As variedades de cana-de-açúcar utilizadas foram a RB863129 nos solos: PAdx (EECAC), LAd (Cucaú), GXve (Salgado) e EKo (Santa Teresa) e a RB855536 no PAd (Pumaty), visto que esta era a variedade disponível e mais utilizada pela Empresa, quando da implantação do ensaio. Referidas variedades são cultivadas comercialmente na região e foram desenvolvidas pelo Programa de Melhoramento Genético da Cana-de-Açúcar (PMGCA), das Universidades Federais integrantes da Rede Interuniversitária para Desenvolvimento do Setor Sucroalcooleiro (RIDESA), cujas características foram descritas por Arizono et al. (1999) e Simões Neto \& Melo (2005).

O manejo dos solos consistiu de preparo e sulcação mecanizados com grade aradora, grade niveladora e sulcação com sulcador de aivecas de duas linhas. A correção da acidez dos solos foi realizada com calcário dolomítico e baseada na recomendação para Pernambuco (IPA, 2008) utilizando-se, como critério, a neutralização dos teores trováveis de $\mathrm{Al}$ ou elevação dos teores trocáveis de $\mathrm{Ca}$ e $\mathrm{Mg}$, aplicando-se o maior valor obtido no cálculo, razão pela qual foram aplicadas 3,0;2,0 e 2,0 t ha ${ }^{-1}$ de calcário para os solos LAd, PAd e GXve, respectivamente. Nos solos PAdx e EKo não foi recomendada a aplicação de calcário pelo critério utilizado.

A adubação nitrogenada e a potássica foram baseadas na recomendação para cana planta, em Pernambuco (IPA, 2008). $\mathrm{Na}$ forma de aplicação utilizada empregou-se todo o N e o K no fundo do sulco de plantio, juntamente com as doses de P; para $\mathrm{N}$, a dose padrão em todos os experimentos foi de $40 \mathrm{~kg} \mathrm{ha}^{-1}$, utilizando-se como fonte o sulfato de amônio e para P 100 $\mathrm{kg} \mathrm{ha}^{-1}$ de $\mathrm{K}_{2} \mathrm{O}$, cuja fonte foi o cloreto de potássio.

As variedades de cana-de-açúcar foram plantadas em março/ 2006 e colhidas em fevereiro de 2007. O material vegetal foi 
coletado na área útil da parcela, amostrando-se ao acaso quatro plantas de cada uma das três linhas centrais, totalizando doze plantas por parcela, as quais foram destinadas à análise tecnológica e seus pesos incluídos na estimativa da produção agrícola.

Os resultados de produção agrícola foram estimados em toneladas de cana por hectare (TCH) após a obtenção dos pesos dos colmos das plantas na área útil da parcela e, com o dado tecnológico de sacarose aparente (pol), foram calculadas as toneladas de açúcar por hectare, expressas em tonelada de pol (TPH). Foram avaliados, também, os valores de sólidos solúveis ( ${ }^{\circ}$ Brix), pureza do caldo (Pureza), fibra na cana (FIBRA), pol da cana (PCC) e açúcares totais recuperáveis (ATR). Todas as análises tecnológicas foram realizadas em laboratório especializado da EECAC.

Os dados das variáveis de produção agrícola e tecnológicos foram submetidos à análise de variância pelo teste $\mathrm{F}$ a 5\% de probabilidade; em seguida, realizou-se análise de regressão para os efeitos significativos. Com a regressão da produção agrícola em função das doses de $\mathrm{P}$, calculou-se a dose que proporcionou a máxima eficiência física (MEF) e correspondeu à produção máxima de colmos. A dose de máxima eficiência econômica (MEE) foi calculada em função da estimativa de $90 \%$ da produção máxima.

Os coeficientes dos componentes de cada modelo foram testados pelo teste $\mathrm{t}$ a $5 \%$ de probabilidade, escolhendo-se os modelos significativos, com maior coeficiente de determinação.

\section{RESULTADOS E DISCUSSÃO}

A produção de cana-de-açúcar em função das doses de $\mathrm{P}$ determinadas para cada solo em função da CMAP (Tabela 5) aumentou, independente do poder tampão de fosfato dos solos, com o PAd apresentando as maiores produtividades e o PAdx as menores.

Os maiores incrementos de TCH e TPH ocorreram com as menores doses de $\mathrm{P}$, indicando limitação dos solos pela deficiência ou baixa disponibilidade deste nutriente, independente de suas características químicas, físicas ou mineralógicas (Tabela 5).

Os resultados aqui obtidos são compatíveis com os observados por Simões Neto \& Melo (2005), que encontraram, para a variedade RB863129, em cana planta, produtividades de $99 \mathrm{t} \mathrm{ha}^{-1}$ de cada colmos e TPH de 14,35. Arizono et al. (1999), encontraram, para a variedade RB855536, em cana planta, valores mais elevados, da ordem de $123,1 \mathrm{t} \mathrm{ha}^{-1}$ de colmos e TPH de 18,54. As menores produções encontradas neste trabalho são devidas, possivelmente, ao ambiente, de vez que a variedade utilizada por esses pesquisadores foi desenvolvida no Estado de São Paulo onde, além do fator solo, a precipitação pluvial é maior que no Nordeste e frequentemente melhor distribuída, favorecendo maior desenvolvimento da cultura.

Com os dados de TCH e TPH como variáveis dependentes das doses de $\mathrm{P}$ aplicadas, obtiveram-se equações de regressão para cada solo (Figura 1A, B, C, D, E); no PAdx os dados de TCH e TPH se ajustaram aos modelos curvilineares, com ponto de máxima produção. Assim, neste solo a adubação fosfatada
Tabela 5. Produção agrícola (TCH) e industrial (TPH) em função do fósforo aplicado nos solos

\begin{tabular}{|c|c|c|c|c|}
\hline \multirow{2}{*}{ Solo* } & \multirow{2}{*}{$\begin{array}{c}\text { Dose de P } \\
\mathrm{kg} \mathrm{ha}^{-1}\end{array}$} & \multirow{2}{*}{ Variedade } & $\mathrm{TCH}$ & TPH \\
\hline & & & \multicolumn{2}{|c|}{$t h a^{-1}$} \\
\hline \multirow{8}{*}{ PAdx } & 0,00 & \multirow{8}{*}{ RB863129 } & 44,75 & 6,09 \\
\hline & 13,20 & & 69,00 & 9,16 \\
\hline & 26,40 & & 71,75 & 9,31 \\
\hline & 52,80 & & 73,75 & 9,30 \\
\hline & 79,20 & & 75,00 & 9,85 \\
\hline & 105,60 & & 76,50 & 9,94 \\
\hline & 132,00 & & 79,00 & 10,41 \\
\hline & Média & & 69,96 & 9,15 \\
\hline \multirow{8}{*}{ LAd } & 0,00 & \multirow{8}{*}{ RB863129 } & 16,67 & 2,40 \\
\hline & 25,39 & & 58,33 & 8,75 \\
\hline & 51,10 & & 72,08 & 11,05 \\
\hline & 102,21 & & 80,83 & 11,77 \\
\hline & 153,31 & & 85,83 & 13,22 \\
\hline & 204,42 & & 90,00 & 13,48 \\
\hline & 255,52 & & 90,00 & 13,35 \\
\hline & Média & & 70,54 & 10,57 \\
\hline \multirow{8}{*}{ PAd } & 0,00 & \multirow{8}{*}{ RB855536 } & 69,00 & 10,18 \\
\hline & 30,02 & & 103,00 & 14,64 \\
\hline & 60,20 & & 108,50 & 16,16 \\
\hline & 126,40 & & 116,00 & 17,25 \\
\hline & 189,60 & & 118,00 & 17,30 \\
\hline & 252,80 & & 123,50 & 17,99 \\
\hline & 316,00 & & 119,50 & 17,42 \\
\hline & Média & & 108,21 & 15,85 \\
\hline \multirow{8}{*}{ GXve } & 0,00 & \multirow{8}{*}{ RB863129 } & 59,42 & 8,74 \\
\hline & 32,80 & & 80,87 & 12,18 \\
\hline & 65,60 & & 87,52 & 13,36 \\
\hline & 131,20 & & 89,50 & 13,28 \\
\hline & 196,80 & & 88,76 & 13,60 \\
\hline & 262,40 & & 86,29 & 13,14 \\
\hline & 328,00 & & 91,96 & 13,67 \\
\hline & Média & & 83,47 & 12,57 \\
\hline \multirow{8}{*}{ EKo } & 0,00 & \multirow{8}{*}{ RB863129 } & 49,58 & 7,41 \\
\hline & 4,00 & & 80,00 & 11,24 \\
\hline & 8,00 & & 85,00 & 12,07 \\
\hline & 16,00 & & 87,50 & 11,82 \\
\hline & 24,00 & & 90,42 & 12,31 \\
\hline & 32,00 & & 94,58 & 13,26 \\
\hline & 40,00 & & 95,42 & 13,39 \\
\hline & Média & & 83,21 & 11,64 \\
\hline
\end{tabular}

PAdx - Argissolo Amarelo Distrocoeso; LAd - Latossolo Amarelo Distrófico; PAd - Argissolo Amarelo Distrófico; GXve - Gleissolo Háplico Eutrófico; EKo - Espodossolo Humilúvico Órtico

proporcionou, sem dúvida, aumentos no teor de $\mathrm{P}$, que deixou de limitar o crescimento e, em contrapartida, as produções agrícola e industrial. Essas variáveis atingiram os valores de máxima produção na resposta à adição de $\mathrm{P}$ (Figura 1A).

No LAd os ajustes dos dados de $\mathrm{TCH}$ e $\mathrm{TPH}$ foram semelhantes aos do PAdx (Figura 1B). A máxima produção obtida indicou que o P não limitou mais as produções agrícola e industrial da cana-de-açúcar, com o incremento das doses, mesmo em solo de elevado poder tampão de $\mathrm{P}$, ou seja, baixo valor de Prem, elevada CMAP e presença de gibsita na fração argila, como o LAd (Tabelas 2 e 3). Ressalta-se o dimensionamento adequado das doses aplicadas e que foram baseadas na CMAP, revelando a importância de características químicas ou físicas dos solos para a recomendação de $\mathrm{P}$, sobretudo para extratores que se desgastam rapidamente com o aumento da capacidade tampão de P do solo. 
A.
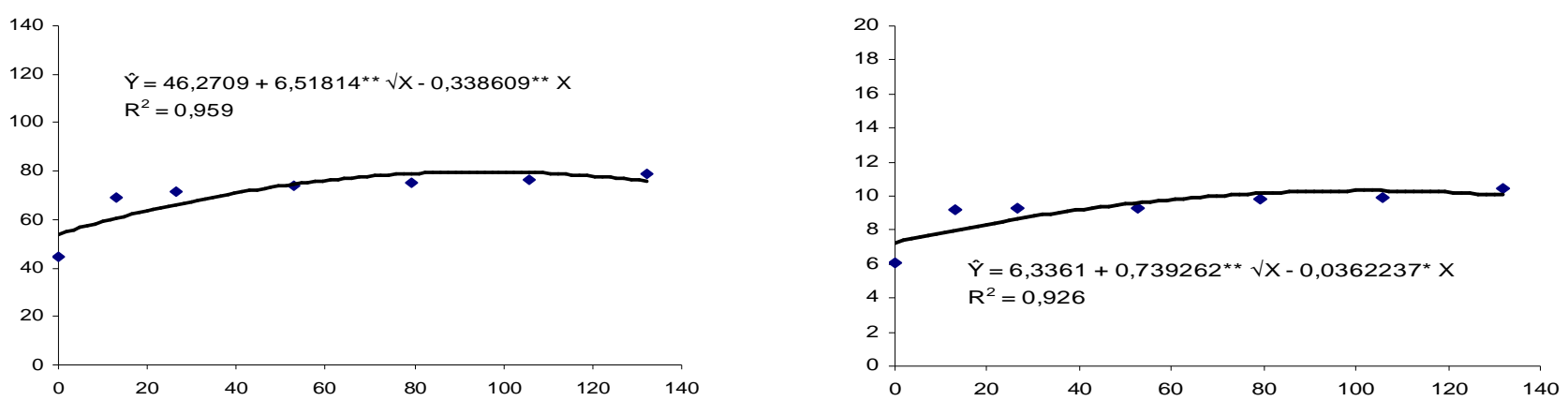

B.
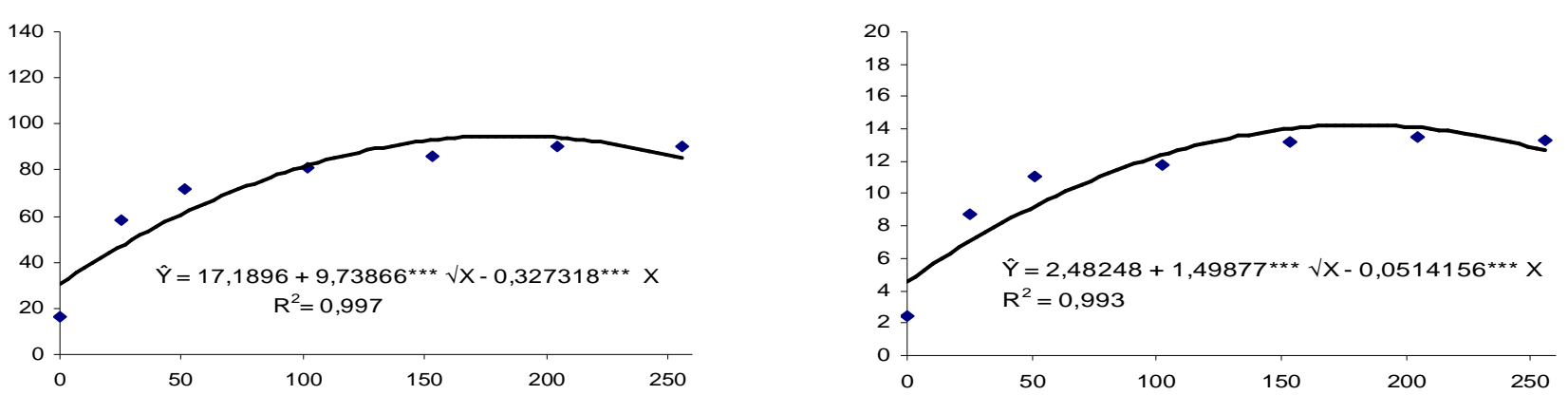

C.
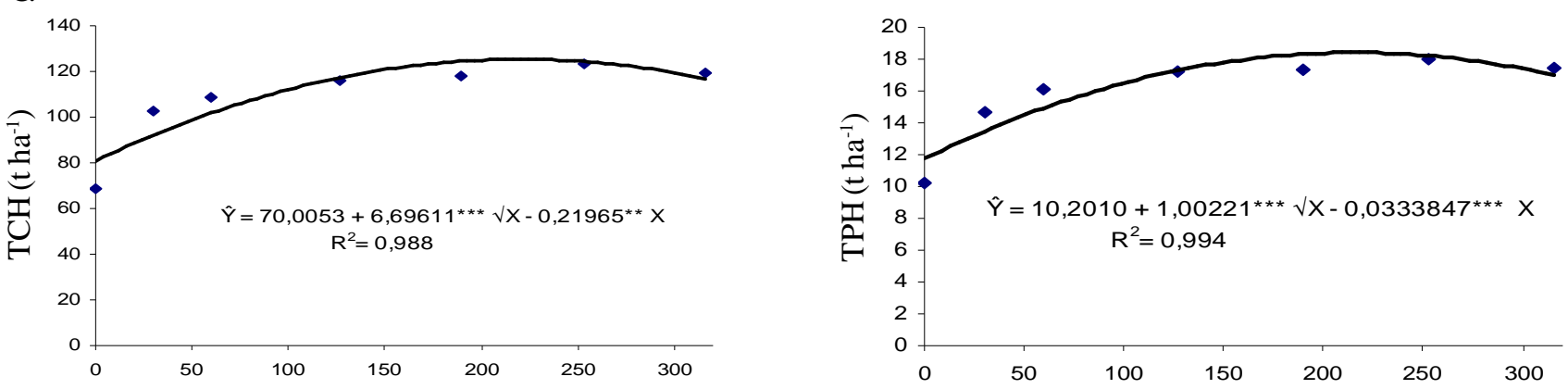

D.
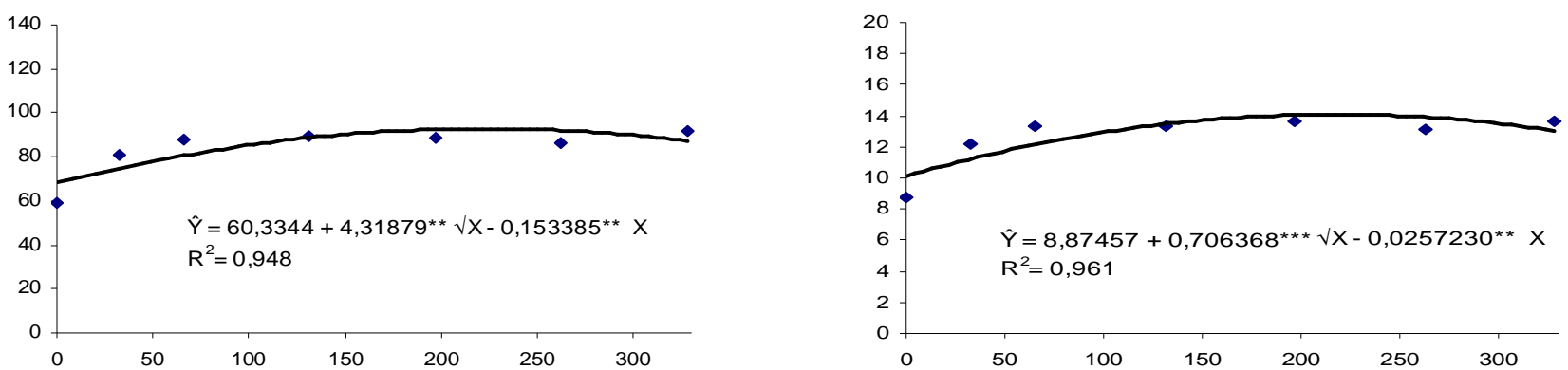

E
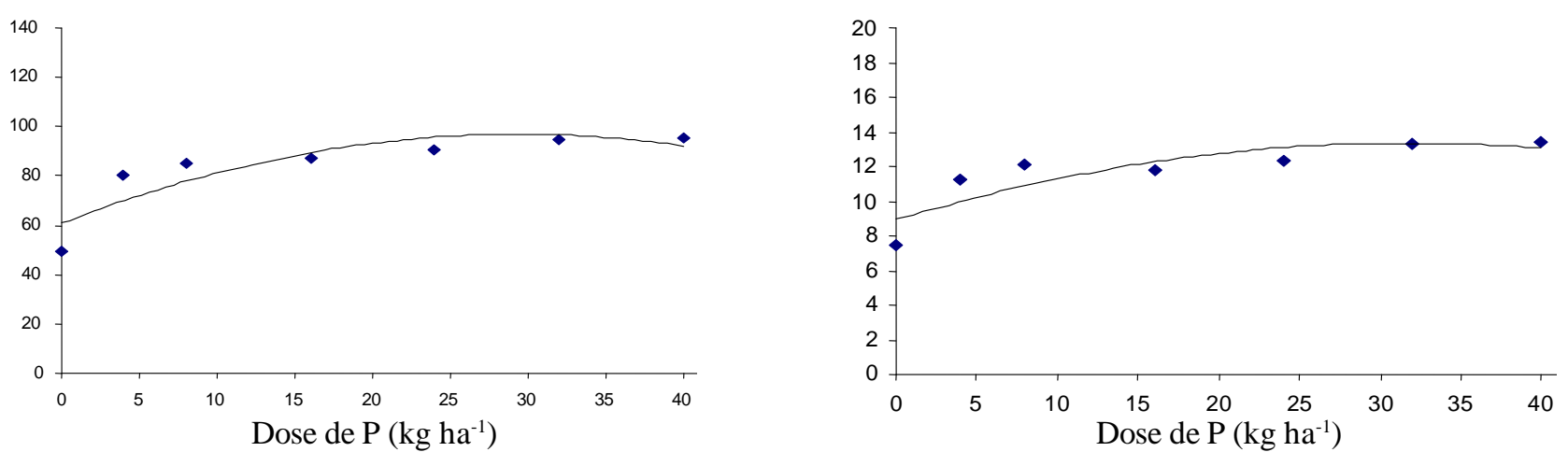

Figura 1. Produção agrícola (TCH ) e industrial (TPH) da cana-de-açúcar como variável dependente do fósforo aplicado em: Argissolo Amarelo distrocoeso (PAdx) (A); Latossolo Amarelo distrófico (LAd) (B); A rgissolo Amarelo distrófico (PAd) (C); Gleissolo Háplico Eutrófico (GXve) (D); Espodossolo Humilúvico Ó rtico (EKo) (E) 
No PAd, os ajustes dos dados de TCH e TPH foram semelhantes aos dos solos PAdx e LAd (Figura 1C); no solo PAd e mesmo tendo mais elevada capacidade de adsorção de $\mathrm{P}$ que o LAd (Tabela 2), com o incremento das doses de P a canade-açúcar respondeu à adubação fosfatada; no GXve os ajustes dos dados de TCH e TPH foram semelhantes aos dos solos PAdx, LAd e PAd (Figura 1D); neste solo a capacidade de adsorção de Pé mais elevada que nos solos LAd e PAd porém se observou, ainda, resposta à adubação fosfatada; no EKo ajustes dos dados de TCH e TPH foram semelhantes aos dos solos PAdx, LAd, PAd e GXve (Figura 1E).

As doses para máxima eficiência econômica (MEE) foram maiores nos solos argilosos LAd, PAd e GXve, seguidas do PAdx e EKo, que apresentaram a menor dose de MEE, correspondendo a cerca de $10 \%$ da dose para o LAd (Tabela 6).

Com exceção do LAd percebe-se, nas curvas de resposta de TCH e TPH em função da aplicação de P(Tabela 5 e Figura 1A, B, C, D, e E), que em ambientes de pesquisa em que se
Tabela 6. Doses de máxima eficiência econômica (M EE) nos solos

\begin{tabular}{ccc}
\hline Solo $^{*}$ & Variedade & $\begin{array}{c}\text { Dose de P (MEE) } \\
\mathbf{k g ~ h}^{-1}\end{array}$ \\
PAdx & RB863129 & 23,4 \\
LAd & RB863129 & 99,9 \\
PAd & RB855536 & 61,4 \\
GXve & RB863129 & 42,6 \\
EKo & RB863129 & 9,7 \\
\hline
\end{tabular}

PAdx - Argissolo Amarelo Distrocoeso; LAd - Latossolo Amarelo Distrófico; PAd - Argissolo Amarelo Distrófico; GXve - Gleissolo Háplico Eutrófico; EKo - Espodossolo Humilúvico Órtico

maximizam os insumos e se exerce certo controle das variações do acaso, o potencial de produção sem a adição de $\mathrm{P}$ é elevado, chegando no PAd a $70 \mathrm{t} \mathrm{ha}^{-1}$ de colmos. Mesmo assim se ressalta a importância do $\mathrm{P}$ aplicado em que, especificamente para este solo, na dose de MEE, a produção se elevou para cerca de 110 t ha $\mathrm{a}^{-1}$, indicando resposta à aplicação do nutriente (Tabela 6).

Tabela 7. Dados tecnológicos em função do fósforo aplicado nos solos

\begin{tabular}{|c|c|c|c|c|c|c|c|}
\hline \multirow{2}{*}{ Solo* } & \multirow{2}{*}{ Variedade } & \multirow{2}{*}{$\begin{array}{c}\text { Dose de P } \\
\mathrm{kg} \mathrm{ha}^{-1}\end{array}$} & FIBRA $^{1}$ & $\mathrm{PCC}^{2}$ & PUREZA $^{3}$ & \multirow{2}{*}{$\begin{array}{c}S^{4}{ }^{4} \\
{ }^{0} \mathrm{BRIX}\end{array}$} & \multirow{2}{*}{$\begin{array}{l}\text { ATR }^{5} \\
\mathrm{~kg} \mathrm{t}^{1}\end{array}$} \\
\hline & & & & $\%$ cana & & & \\
\hline \multirow{8}{*}{ PAdx } & \multirow{8}{*}{ RB863129 } & 0 & 14,80 & 13,60 & 84,39 & 20,02 & 131,35 \\
\hline & & 13,20 & 14,66 & 13,28 & 83,87 & 19,62 & 128,50 \\
\hline & & 26,40 & 14,39 & 12,98 & 83,42 & 19,20 & 125,89 \\
\hline & & 52,80 & 15,11 & 12,58 & 82,69 & 19,00 & 122,31 \\
\hline & & 79,20 & 14,88 & 13,15 & 83,56 & 19,57 & 127,35 \\
\hline & & 105,60 & 14,74 & 12,97 & 83,03 & 19,39 & 125,88 \\
\hline & & 132,00 & 15,13 & 13,16 & 84,39 & 19,47 & 127,20 \\
\hline & & Média & 14,82 & 13,10 & 83,62 & 19,47 & 126,92 \\
\hline \multirow{8}{*}{ LAd } & \multirow{8}{*}{ RB863129 } & 0 & 14,68 & 14,51 & 88,91 & 20,23 & 138,65 \\
\hline & & 25,39 & 13,76 & 15,00 & 88,43 & 20,70 & 143,41 \\
\hline & & 51,10 & 13,75 & 15,31 & 88,80 & 21,03 & 146,14 \\
\hline & & 102,21 & 14,34 & 14,56 & 88,63 & 20,25 & 139,25 \\
\hline & & 153,31 & 13,63 & 15,39 & 88,06 & 21,28 & 147,11 \\
\hline & & 204,42 & 14,19 & 14,97 & 89,42 & 20,58 & 142,84 \\
\hline & & 255,52 & 13,78 & 14,84 & 87,71 & 20,65 & 142,11 \\
\hline & & Média & 14,02 & 14,94 & 88,57 & 20,67 & 142,79 \\
\hline \multirow{8}{*}{ PAd } & \multirow{8}{*}{ RB855536 } & 0 & 15,52 & 14,78 & 89,83 & 20,70 & 140,87 \\
\hline & & 30,02 & 14,42 & 14,23 & 85,48 & 20,55 & 136,97 \\
\hline & & 60,20 & 14,60 & 14,89 & 88,63 & 20,80 & 142,30 \\
\hline & & 126,40 & 14,47 & 14,85 & 88,79 & 20,65 & 141,85 \\
\hline & & 189,60 & 14,90 & 14,66 & 87,71 & 20,78 & 140,29 \\
\hline & & 252,80 & 15,76 & 14,59 & 89,37 & 20,63 & 139,20 \\
\hline & & 316,00 & 14,27 & 14,58 & 86,72 & 20,68 & 139,87 \\
\hline & & Média & 14,85 & 14,65 & 88,07 & 20,68 & 140,19 \\
\hline \multirow{8}{*}{ GXve } & \multirow{8}{*}{ RB863129 } & 0 & 14,54 & 14,74 & 89,81 & 20,30 & 140,56 \\
\hline & & 32,80 & 13,81 & 15,08 & 88,86 & 20,73 & 143,98 \\
\hline & & 65,60 & 13,74 & 15,27 & 89,08 & 20,93 & 145,69 \\
\hline & & 131,20 & 13,98 & 14,84 & 87,81 & 20,70 & 142,03 \\
\hline & & 196,80 & 13,77 & 15,32 & 92,37 & 20,25 & 145,39 \\
\hline & & 262,40 & 13,94 & 15,23 & 90,96 & 20,50 & 144,88 \\
\hline & & 328,00 & 13,77 & 14,87 & 88,33 & 20,55 & 142,21 \\
\hline & & Média & 13,94 & 15,05 & 89,60 & 20,56 & 143,53 \\
\hline \multirow{8}{*}{ EKo } & \multirow{8}{*}{ RB863129 } & 0 & 14,65 & 14,93 & 89,51 & 20,65 & 142,37 \\
\hline & & 4,00 & 14,41 & 14,05 & 85,71 & 20,23 & 135,22 \\
\hline & & 8,00 & 15,06 & 14,22 & 88,66 & 20,00 & 136,03 \\
\hline & & 16,00 & 15,12 & 13,52 & 85,10 & 19,80 & 130,43 \\
\hline & & 24,00 & 14,24 & 13,59 & 85,85 & 19,48 & 130,98 \\
\hline & & 32,00 & 14,57 & 14,03 & 87,10 & 19,93 & 134,68 \\
\hline & & 40,00 & 14,88 & 14,04 & 86,58 & 20,18 & 134,84 \\
\hline & & Média & 14,70 & 14,06 & 86,93 & 20,04 & 134,94 \\
\hline
\end{tabular}

${ }^{1}$ Fibra na cana; ${ }^{2}$ Pol da cana; ${ }^{3}$ Pureza do caldo; ${ }^{4}$ Sólidos solúveis; ${ }^{5}$ Açúcares totais recuperáveis

PAdx - Argissolo Amarelo Distrocoeso; LAd - Latossolo Amarelo Distrófico; PAd - Argissolo Amarelo Distrófico; GXve - Gleissolo Háplico Eutrófico; EKo - Espodossolo Humilúvico Órtico 
Por outro lado, essas curvas de resposta de TCH e TPH à aplicação de $\mathrm{P}$ em diferentes solos, mostraram a necessidade de modificar as recomendações de $\mathrm{P}$ que não consideram características do solo que refletem o poder tampão de fosfato, quando o extrator para avaliar o $\mathrm{P}$ disponível for o Melhich-1 (variável de acordo com a capacidade tampão de $\mathrm{P}$ do solo), como se faz em Pernambuco. Essas recomendações certamente subestimam as doses de $\mathrm{P}$ em solos argilosos e as superestimam em solos arenosos.

Para o EKo a dose de MEE foi de 9,7 $\mathrm{kg} \mathrm{ha}^{-1}$ de P (Tabela 6), justificada por ser o solo que apresenta a menor CMAP e menor teor de argila (Tabela 2). Esta dose corresponde a aproximadamente $23 \mathrm{~kg} \mathrm{ha}^{-1}$ de $\mathrm{P}_{2} \mathrm{O}_{5}$ praticamente metade da menor dose recomendada pelo atual sistema de recomendação de adubação para o estado de Pernambuco (IPA, 2008). Considerando esses resultados pode-se reduzir o custo da adubação fosfatada em solos arenosos, como o EKo, obtendo-se as mesmas produtividades. Como os níveis críticos em solos de menor poder tampão, quando o extrator é o Melhich-1, são maiores e as doses recomendadas não consideram as características químicas, físicas e/ou mineralógicas dos solos, como em Pernambuco, as adubações atualmente recomendadas podem estar superestimadas, sobremaneira para esses solos.

Em estudo de doses econômicas, Alvarez et al. (1991), discutindo os resultados de dezenove ensaios de adubação de cana-de-açúcar efetuados em Latossolo Roxo, em diferentes regiões paulistas, constataram aumentos médios de produção de 15,2, 10,0 e 21,3 tha-1 de colmos nas doses correspondentes a MEE de N, P e K, respectivamente. Mesmo com esse incremento de produção obtido com referidas doses, constatouse que elas estavam superestimadas em relação às recomendações sugeridas na época, indicando que variáveis econômicas sejam criteriosamente consideradas nas recomendações de adubação, maximizando as relações custo/ benefício da adubação.

Os dados tecnológicos evidenciaram que as doses de $\mathrm{P}$ não influenciaram as características industriais das variedades utilizadas no ensaio, ou seja, a qualidade da matéria-prima para industrialização (Tabela 7). Resultados semelhantes obtiveram Korndörfer \& Melo (2009) que, avaliando o efeito de diferentes formas de $\mathrm{P}$ em características agroindústrias da variedade de cana-de-açúcar SP71-1406, verificaram que os adubos fosfatados aplicados ao solo não tiveram correlação com características industriais, como $\mathrm{P}_{2} \mathrm{O}_{5}$ no caldo, $\mathrm{PCC}$ e ATR.

Todos os valores obtidos relacionados às características tecnológicas avaliadas, permaneceram acima dos índices da cana padrão para industrialização em Pernambuco, sendo os melhores indicadores industriais registrados para as médias obtidas nos solos GXve e LAd (Tabela 7).

A característica tecnológica que atualmente remunera a matéria-prima é o açúcar total recuperável (ATR). O padrão para o estado de Pernambuco é $119 \mathrm{~kg} \mathrm{t}^{-1}$ baseado em convenção dos órgãos de classe do setor sucroalcooleiro. $\mathrm{O}$ ATR da cana-de-açúcar cultivada nos solos LAd, GXVe e PAd foi considerado alto para a região, bem superior ao ATR obtido na cana-de-açúcar cultivada nos solos EKo e PAdx (Tabela 7).

\section{CONCLUSÕES}

1. A adubação fosfatada nas condições de cana planta influenciou positivamente a produção agrícola e industrial.

2. Os valores de Açúcares Totais Redutores não foram influenciados pelas doses de P; entretanto, foram mais elevados nos solos com maior poder tampão de fosfato.

3. As doses de P não influenciaram as características industriais, sólidos solúveis FIBRA e PCC.

4. A capacidade máxima de adsorção de fósforo deve ser considerada na recomendação de adubação fosfatada, em especial quando o extrator para estimativa do $\mathrm{P}$ disponível for sensível à capacidade tampão de fosfato do solo.

\section{AgradeCimentos}

À Diretoria e gerência agrícola das unidades agroindustriais em que foram conduzidos os experimentos: Usina Cucaú, Usina Pumaty, Usina Salgado e Usina Santa Teresa em Pernambuco, e ao CNPq, pelo apoio financeiro.

\section{LITERATURA CITADA}

Alvarez, R.; Wutke, A. C. P.; Arruda, H. V.; van Raij, B.; Gomes, A. C.; Zink, F. Adubação da cana-de-açúcar: XIV. Adubação NPK em Latossolo Roxo. Bragantia, v.50, p.359-374, 1991.

Alvarez V., V. H.; Fonseca, D. M. Definição de doses de fósforo para determinação da capacidade máxima de adsorção de fosfatos e para ensaios em casa de vegetação. Revista Brasileira da Ciência do Solo, v.14, p.44-55, 1990.

Alvarez V., V. H.; Novais, R. F.; Dias, L. E.; Oliveira, J. A. Determinação e uso do fósforo remanescente. Viçosa: Sociedade Brasileira de Ciência do Solo, 2000. p.27-33. Boletim Informativo, 25.

Arizono, H.; Matsuoka, S.; Gheller, A. C. A.; Masuda, Y.; Hoffmann, H. P.; Bassinell, A. J. Guia das principais variedades RB. Araras: Universidade Federal de São Carlos, 1999. 15p. Boletim Técnico

Braga, J. M.; Defelipo, B. V. Determinação espectrofotométrica de fósforo em extrato de solo e material vegetal. Revista Ceres, v.21, p.73-85, 1974.

Broggi, F.; Oliveira, A. C.; Freire, F. J.; Freire, M. B. G. dos S.; Nascimento, C. W. A. do. Adsorption and chemical extraction of phosphorus as a function of soil incubation time. Revista Brasileira de Engenharia Agrícola e Ambiental, v.14, p.3238, 2010.

Bovi, R.; Serra, G. E. Folhas verdes, folhas secas, fibra do colmo e clarificação do caldo de cana-de-açúcar. Scientia Agricola, v.58, p.457-463, 2001.

Coffin, D. E. A method of determination of free iron in soil and clays. Canadian Journal of Soil Science, v.43, p.7-17, 1963.

Corrêa, R. M.; Nascimento, C. W. A.; Freire, F. J.; Souza, S. K. S. C.; Ferraz, G. B. Disponibilidade e níveis críticos de fósforo em milho e solos fertilizados com fontes fosfatadas. Revista Brasileira de Ciências Agrárias, v.3, p.212-224, 2008. 
Dantas Neto, J.; Figueiredo, J. L. da C.; Farias, C. H. de A.; Azevedo, H. M. de; Azevedo, C. A. de. Resposta da canade-açúcar, primeira soca, a níveis de irrigação e adubação de cobertura, Revista Brasileira de Engenharia Agrícola e Ambiental, v.10, p.283-288, 2006.

Demattê, J. L. I. Recuperação de manutenção da fertilidade do solo. Piracicaba: Potafos, 2005. 24p. Informações Agronômicas - Boletim Informativo, 111.

EMBRAPA - Empresa Brasileira de Pesquisa Agropecuária. Manual de métodos de análise de solo. Rio de Janeiro: Centro Nacional de Pesquisa de Solos, 1997. 212p.

IPA - Empresa Pernambucana de Pesquisa Agropecuária. Recomendações de Adubação para o Estado de Pernambuco ( $2^{\mathrm{a}}$ aproximação). 2.ed. Recife: Empresa Pernambucana de Pesquisa Agropecuária, 2008. 198p.

Korndörfer, K. H.; Melo, S. P. de. Fontes de fósforo (fluída ou sólida) na produtividade agrícola e industrial da cana-deaçúcar. Ciência e Agrotecnologia, v.33, p.92-97, 2009.

Mehra, O. P.; Jackson, M. L. Iron oxide removal from clays by dithionite - citrate - bicarbonate system buffered with sodium bicarbonate. Clays and Clay Minerals, v.7, p.317$327,1960$.

Morelli, J.; Nelli, E. J.; Baptistella, J. R.; Demattê, J. L. Termofosfato na produtividade da cana-de-açúcar e nas propriedades químicas de um solo arenoso de baixa fertilidade. Revista Brasileira de Ciência do Solo, v.15, p.57$61,1991$.
Oliveira, R. A.; Donas, E.; Zambon, J. L. C.; Weber, H.; Ido, O. T.; Zuffellato-Ribas, K. C.; Koecher, H. S.; Silva, D. K. T. Crescimento e desenvolvimento de três cultivares de canade-açúcar no Estado do Paraná: Taxas de crescimento. Revista Sciencia Agrária, v.6, p.85-89, 2005.

Santos, V. R. dos; Moura Filho, G.; Albuquerque, A. W. de; Costa, J. P. V. da; Santos, C. G. dos; Santos, A. C. I. dos. Crescimento e produtividade agrícola de cana-de-açúcar em diferentes fontes de fósforo. Revista Brasileira de Engenharia Agrícola eAmbiental, v.13, p.389-396, 2009.

Silva, E. M. B.; Freire, F. J.; Santos, M. V. F.; Silva, T. J. A.; Freire, M. B. G. S. Níveis críticos de fósforo para Brachiaria brizantha e suas relações com características físicas e químicas em solos de Pernambuco. Revista Brasileira de Ciência do Solo, v.28, p.281-288, 2004.

Silva, M. A.; Nóbrega, J. C. A.; Curi, N.; Siqueira, J. O.; Marques, J. J. G. S.; Motta, P . E. F. Frações de fósforo em Latossolos. Pesquisa Agropecuária Brasileira, v.38, p.1197-1207, 2003.

Simões Neto, D. E.; Melo, L. J. O. T. Lançamento de novas variedades RB de cana-de-açúcar. Recife: Imprensa Universitária/UFRPE, 2005. 28p.

Simões Neto, D. E.; Oliveira, A. C.; Freire, F. J.; Freire, M. B. G. dos S.; Nascimento, C. W. A. do; Rocha, A. T. da. Extração de fósforo em solos cultivados com cana-deaçúcar e suas relações com a capacidade tampão. Revista Brasileira de Engenharia Agrícola e Ambiental, v.13, p.840848, 2009. 